\title{
Direito ao conhecimento da origem biológica na reprodução humana assistida: reflexões bioéticas e jurídicas \\ Camila Vasconcelos ${ }^{1}$, Cátia Lustosa ${ }^{2}$, Ana Thereza Meirelles ${ }^{3}$, Anderson Vieira Aranha ${ }^{4}$, Volnei Garrafa ${ }^{5}$
}

\section{Resumo}

Este artigo discute o direito ao conhecimento da origem biológica da pessoa gerada por técnica de reprodução humana assistida, apresentando argumentos e problemas envolvidos nesse complexo processo que inclui diferentes interesses. Nesse sentido, foi desenvolvido um estudo hipotético-dedutivo, com base referencial teórica sustentada na bioética e no direito, na medida em que esses dois campos se interseccionavam quanto à natureza da matéria. $\mathrm{O}$ estudo avança, ainda, abordando os riscos decorrentes dos avanços tecnológicos $\mathrm{e}$ das expectativas dos sujeitos envolvidos, inclusive a vulnerabilidade, o consentimento para doação de gametas e o anonimato dos doadores. Discute, também, os conceitos de "identidade genética" e direito ao conhecimento da "origem biológica", traçando analogia com a legislação brasileira relativa à adoção. Por fim, trata do chamado "pertencimento do segredo", refletindo sobre os argumentos encontrados na literatura afim, inclusive o contexto de "desbiologização" atualmente defendido pelos tribunais superiores.

Palavras-chave: Bioética. Direito à saúde. Técnicas reprodutivas. Privacidade.

\section{Resumen}

\section{Derecho al conocimiento del origen biológico en reproducción humana asistida: reflexiones bioéticas y legales}

Este artículo aborda el derecho al conocimiento del origen biológico de la persona generada por técnica de reproducción humana asistida, presentando los argumentos y problemas implicados en este complejo proceso que involucra diferentes intereses. En este sentido, se ha desarrollado un estudio hipotético-deductivo, con sustento teórico en bioética y derecho, y la intersección de estos dos campos respecto a la naturaleza del tema. El estudio avanza, haciendo relación a los riesgos de los avances tecnológicos y las expectativas de los participantes, la vulnerabilidad, el consentimiento para la donación de gametos y el anonimato de los donantes. Son analizados también los conceptos de "identidad genética" y el derecho a conocer el "origen biológico", haciendo una analogía con la legislación brasileña relativa a la adopción. Por último, se aborda la llamada "pertenencia del secreto ", al reflexionar sobre los argumentos de la literatura al respecto, incluyendo el contexto de " desbiologización " actualmente defendida por los tribunales superiores.

Palabras-clave: Bioética. Derecho a la salud. Técnicas reproductivas. Privacidad.

\section{Abstract}

\section{Right to knowledge of biological origin in Human Assisted Reproduction: bioethical and legal reflections}

This article discusses the right to know the biological origins of a person generated by the Heterologous Human Reproduction technique, presenting arguments and issues related to this complex process, which involves different interests. In this sense, a hypothetical-deductive study is developed based on intersections of nature and content between Bioethics and Law. The study progresses by approaching the risks brought by technological advances and the expectations of all subjects involved, as well as vulnerabilities, the need for consent for gamete donation and donor anonymity. It further debates the concepts of "genetic identity" and the right to know one's "biological origins", drawing an analogy with Brazilian adoption law. Finally, the study addresses the so-called "secrecy right", considering arguments found in legal literature, including the idea of "de-biologization" currently defended by the Brazilian higher courts.

Keywords: Bioethics. Right to health. Reproductive techniques. Privacy.

1. Doutoranda camila.vasconcelos@ufba.br - Universidade de Brasília, Brasília/DF, Brasil 2. Mestranda catialustosa@gmail.com Universidade de Brasília, Brasília/DF, Brasil 3. Doutoranda anatherezameirelles@gmail.com - Universidade Federal da Bahia, Salvador/ BA, Brasil 4. Mestre aranhaav@gmail.com - Centro Universitário São Camilo, São Paulo/SP, Brasil. 5. Pós-doutor garrafavolnei@gmail. com - Universidade de Brasília, Brasília/DF, Brasil.

Camila Vasconcelos - Faculdade de Medicina, Eixo Ético-humanístico, Praça XV de Novembro, s/no, Largo do Terreiro de Jesus CEP 40025010. Salvador/BA, Brasil. 
Embora as técnicas de reprodução humana assistida (RHA) tenham sido introduzidas no Brasil no início dos anos $1980^{1}$, o país até hoje não possui legislação própria a respeito da matéria. Nestes quase 30 anos de utilização, as práticas relacionadas com as novas tecnologias reprodutivas desenvolvidas no país têm se pautado basicamente pelas resoluções normativas produzidas pelo Conselho Federal de Medicina (CFM) e dirigidas prioritariamente aos médicos. Mais recentemente, o Conselho baixou a Resolução CFM 2.013/13 2, regulamentando nacionalmente a RHA no que concerne à atuação dos médicos - profissionais responsáveis pela assistência técnica e ética para a reprodução artificializada -, fato que terminou, indiretamente, por normatizar a prática, haja vista o vazio legislativo a respeito do tema.

No Código Civil de $2002{ }^{3}$ constam apenas abordagens isoladas sobre RHA. Assim, o debate encontra-se aberto, gerando dificuldades para a resolução de conflitos sociais, éticos e jurídicos nas mais diversas instâncias e situações. Tal circunstância justifica e estimula a reflexão ética sobre o assunto, ao lado de outras reflexões similares que já despontam na literatura especializada.

A legislação atual não é contrária à realização de tais técnicas ${ }^{4}$. Isso não significa, entretanto, que estejamos afastados dos diversos dilemas éticos que podem advir desses procedimentos, tanto em uma conjuntura de situações emergentes que, segundo Garrafa, são proporcionadas por avanços como aqueles alcançados no campo da engenharia genética e seus desdobramentos ${ }^{5}$, quanto de situações persistentes, que segundo o mesmo autor estão relacionadas principalmente com a falta de universalidade no acesso das pessoas aos bens de consumo sanitário e à utilização equânime desses benefícios por todos os cidadãos indistintamente ${ }^{5}$. Dadas as características da RHA, bem como seus desdobramentos na dimensão social, pode-se caracterizar a prática em ambas as situações.

A questão aqui exposta, portanto, consiste em um problema concreto a ser enfrentado no debate bioético não somente quanto às decisões éticas sobre o regramento dos avanços registrados na sociedade no que se refere à utilização das técnicas de reprodução assistida, mas também no sentido da dificuldade no acesso público a esses avanços.

\section{Método}

O presente estudo tem como contexto a discussão acerca da possibilidade de compreensão do conhecimento da origem biológica como direito da pessoa gerada por técnica de RHA heteróloga, objetivando apresentar argumentos bioéticos e jurídicos relacionados ao assunto, bem como suas possíveis interpretações e riscos.

Para tanto, a construção da pesquisa partiu de estudo hipotético-dedutivo, com revisão e análise de referencial teórico da bioética e do direito, já que essas duas áreas do conhecimento se interseccionam quanto à natureza da matéria. A análise do problema incorporou, ainda, instrumentos bioético-jurídicos internacionais para a observância de determinações éticas consensualmente construídas pelas comunidades científico-acadêmica e política mundiais.

\section{Reprodução humana assistida no Brasil}

A preocupação, no contexto brasileiro, a respeito dos possíveis dilemas sobre a origem genética dos indivíduos foi levantada inicialmente em 1978, no Congresso Brasileiro de Medicina Legal, e denominada naquela oportunidade de "ancestralidade" dos nascidos, tendo em vista os primeiros resultados internacionais obtidos na época com a fecundação humana extracorpórea ${ }^{6}$. Naquele momento, a imprensa internacional voltava sua atenção especialmente para o caso Louise Brown, na Inglaterra. E, em 1984, as discussões sobre a RHA começaram também no Brasil, após o nascimento de Anna Paula Caldeira. Em ambas as situações empregou-se a fertilização in vitro (FIV) como técnica inovadora.

Dentre as diferentes técnicas de reprodução humana assistida hoje utilizadas, destacam-se, para fins da presente análise, a inseminação artificial e a fertilização in vitro, nas quais se utiliza material germinativo de doadores.

O CFM, por meio da Resolução CFM 2.013/13², considera que o avanço do conhecimento científico permitiu o encontro de soluções para os problemas relativos à reprodução humana. Tal avanço, que hoje já alcança o cotidiano, segundo o próprio Conselho, carece de normas adequadas para a sua utilização, o que de certo modo a Resolução CFM 2.013/13 tenta resolver por meio de seus Princípios Gerais. Igualmente, o referido documento afirma o papel auxiliar e facilitador das técnicas de RHA, cuja utilização é considerada legítima, na medida em que se apresenta como ferramenta portadora de efetiva probabilidade de êxito. A normativa permite, ainda, a utilização das técnicas sob um anterior juízo de ponderação entre benefícios e riscos graves tanto à 
saúde do paciente que usufrui dos avanços, quanto à saúde daquele que é apontado como possível descendente.

\section{Avanços tecnológicos, riscos e expectativas dos sujeitos envolvidos}

Inicialmente, cabem duas breves reflexões para a análise central do assunto. A primeira diz respeito aos riscos à saúde advindos dos avanços tecnológicos que requerem a avaliação acerca dos possíveis prejuízos, situação que remete ao princípio de não maleficência, o qual sugere a obrigação de não se causar dano intencional a ninguém, além de não prejudicar, abstendo-se de impedir a realização dos interesses de terceiros. No mesmo contexto, há que se considerar, igualmente, o princípio de beneficência, que propõe a promoção do agir para o bem em sentido lato, abarcando ações que pretendem o benefício em geral, e avaliando-se as desvantagens que possam decorrer. Ambos os princípios foram assim formulados por Beauchamp e Childress nos primórdios da bioética ${ }^{7}$.

Guardando sentido teórico similar, mas inserindo-se em dimensão mais abrangente, encontra-se o artigo 4ㅇda Declaração Universal sobre Bioética e Direitos Humanos, formulada pela Unesco em 2005, que trata especificamente do princípio de benefício e dano: Os benefícios diretos e indiretos a pacientes, sujeitos de pesquisa e outros indivíduos afetados devem ser maximizados e qualquer dano possível a tais indivíduos deve ser minimizado, quando se trate da aplicação e do avanço do conhecimento científico, das práticas médicas e tecnologias associadas ${ }^{8}$.

A essas reflexões pode-se acrescentar também o princípio da responsabilidade, proposto por Hans Jonas $^{9}$, que sugere a responsabilização dos seres humanos por seus atos no uso de novas tecnologias. Em sua proposta de construção de uma nova ética para a civilização tecnológica, esse autor chama a atenção para o fato de que as consequências das decisões e medidas hoje tomadas irão recair sobre as gerações futuras, às quais caberá o ônus de enfrentá-las e pagar por seu preço.

A segunda reflexão se relaciona com a probabilidade de sucesso adiante da possível expectativa dos sujeitos envolvidos. Nesse sentido, tomou-se como referência o estudo realizado por Samrsla e colaboradores ${ }^{10}$, que investigou a expectativa de mulheres à espera de tratamento por meio de técnicas de RHA em um hospital público brasileiro. Entrevistando 51 mulheres, dentre elas pacientes recém-encaminhadas e pacientes já diagnosticadas com infertilidade aguardando na fila de espera para atendimento, os autores identificaram sua expectativa quanto à maternidade, bem como à dúvida sobre a real possibilidade de serem beneficiadas pelo tratamento. Ainda segundo o estudo, essa possibilidade diminuiu de modo dramático pelo insuficiente número de vagas no sistema de atendimento e pela insuficiência de material e medicamentos disponibilizados aos tratamentos. Em consequência, o tempo de espera na instituição pública aumentava enormemente, ocasionando significativo avanço na idade das mulheres, que, inicialmente jovens, passavam paulatinamente a uma indesejada situação de gravidez de risco.

Nesses termos, fica corroborada a ideia de que a liberdade de procriar, entendida como afirmação da demanda dos pacientes por assistência na saúde, participa das questões relativas à alocação de recursos públicos, segundo aduz Corrêa ${ }^{11}$. Assim, tanto a constatação prévia de efetiva probabilidade de êxito da técnica nas pacientes, quanto a anterior verificação de recursos disponíveis para tal intento, apresentam-se como instrumentos de proteção aos sujeitos que pretendem se beneficiar da RHA.

\section{A quem se destinam as técnicas de RHA no Brasil?}

Abordando a liberdade dos sujeitos de procriar ou não, Mori ${ }^{12}$ denomina essas duas situações de liberdade positiva e liberdade negativa, respectivamente. Para o autor, o perfil da liberdade no âmbito da procriação envolve a escolha autônoma e voluntária, que separa os conceitos de sexualidade e procriação, apresentando-se, em ambas as circunstâncias, como uma ideia de autorrealização da pessoa. Essa linha de reflexão, contudo, colide com a concepção tradicional do casamento, entendida por esse autor como instituição social encarregada de controlar a transmissão da vida de uma geração a outra. Nesses termos, observa-se a mudança da perspectiva brasileira atual acerca do casamento e das relações estáveis, na medida em que a instituição familiar recebe novas roupagens aptas a resguardar o direito à liberdade e à igualdade e o princípio fundamental da dignidade humana. Exemplifica isso o fato de serem reconhecidas no país tanto as uniões homossexuais, afirmadas como famílias homoafetivas, quanto as famílias monoparentais, de cunho social ou biológico, formadas por qualquer dos pais e seus descendentes ${ }^{13}$. 
Diversamente do texto anterior da Resolução CFM 1.358/92 ${ }^{14}$, que abordava a matéria, a Resolução CFM 1.957/10 já admitia como pacientes das técnicas de RHA todas as pessoas capazes, e não mais apenas a mulher, o que pressupunha, ainda, a aprovação do cônjuge ou do companheiro ${ }^{15}$ em caso de essa mulher encontrar-se casada ou em união estável. Atualmente, a Resolução CFM 2.013/13 manteve a disposição para todas as pessoas, ressaltando, ainda mais claramente, que é permitido o uso das técnicas de RA para relacionamentos homoafetivos e pessoas solteiras ${ }^{2}$, em que pese ter mencionado a possibilidade de recusa da prática, pelo médico, tendo em vista o exercício do direito de objeção de consciência.

De todo modo, em suas poucas abordagens sobre as técnicas de RHA, o Código Civil ainda contempla esse enfoque quando, no artigo 1.597, caput e inciso $\mathrm{V}$, considera presumidamente concebidos na constância do casamento os filhos havidos por inseminação artificial heteróloga, desde que tenha prévia autorização do marido. Neste mesmo artigo presumem-se como filhos também aqueles havidos por fecundação artificial homóloga, mesmo que falecido o marido e havidos, a qualquer tempo, quando se tratar de embriões excedentários, decorrentes de concepção artificial homóloga ${ }^{3}$.

Não obstante a presente discussão sobre a necessidade de consentimento por ocasião da geração de filho com material genético de parceiro diverso, o enfoque neste estudo não perpassa as considerações sobre gênero em uniões estáveis e matrimônios - debate importante, mas que foge aos objetivos desta pesquisa. Entretanto, considerou-se indispensável ressaltar a relevância dessa discussão na literatura especializada, que trata da valorização da constituição social dos laços afetivos que corroboram a perspectiva relacional dos vínculos socialmente ou biologicamente formados entre casais heteroafetivos ou homoafetivos, sobretudo nas circunstâncias em que vulnerabilidades sociais estão presentes.

\section{Vulnerabilidade social, consentimento para doação de gametas e anonimato}

Um dado relevante, colhido pelo já mencionado estudo de Samrsla e colaboradores ${ }^{10}$, foi a constatação de que a maior parte das mulheres entrevistadas que aguardavam tratamento ao longo do tempo expressou a vontade de doar óvulos em troca de gratuidade para seus próprios tratamen- tos. Essa constatação remete à reflexão a respeito da vulnerabilidade das pessoas que se submetem às técnicas, sobretudo quando postas em um contexto de evidente fragilidade social e econômica.

Corrêa e Diniz informaram que, até o ano 2000, o desenvolvimento das técnicas de RHA no Brasil dava-se em $99 \%$ dos casos na iniciativa privada, em um contexto em que clínicas particulares promoviam cursos e contavam com mulheres voluntárias ${ }^{16}$. As mesmas autoras afirmam ainda a paradoxal circunstância de significativa visibilidade e difusão das técnicas de RHA, em detrimento do contexto social em que as dificuldades de acesso aos serviços de saúde se mantinham evidentes.

Diante desses fatos, cabem duas interrogações: há vulnerabilidade entre os sujeitos que doam ou essas doações consistem unicamente em manifestações de vontade deliberadas com fim altruísta, sem coerção advinda de circunstâncias de fragilidade? Pode-se situar a eventual vulnerabilidade como acréscimo aos argumentos contrários à quebra do sigilo para conhecimento da origem biológica das pessoas nascidas?

Cogitemos que as pessoas doadoras de determinado material estavam sendo submetidas a técnicas de RHA e não obtiveram sucesso, apesar da expectativa. Cogitemos, ainda, que essas mesmas pessoas doadoras encontrem, adiante, pessoas à procura de suas origens biológicas, com as quais não terão laço de parentesco social constituído, embora tenham vínculo biológico. Nessa situação se estaria diante de um possível problema de ordem moral e social a ser discutido pela bioética, no qual estão envolvidos indivíduos fragilizados pelo não alcance de suas expectativas e restritos quanto ao direito de participação familiar, com outro indivíduo que representa a condição de filho segundo os moldes de filiação biológica.

Coloca-se, então, a discussão a respeito do ato de doar nessa prática, sua concordância e esclarecimentos prévios. A Resolução CFM 2.013/13 obriga os médicos a obter o consentimento informado de todos os pacientes submetidos às técnicas de reprodução assistida. Além disso, a mesma norma prescreve que os aspectos médicos envolvendo a totalidade das circunstâncias da aplicação de uma técnica de RA serão detalhadamente expostos, bem como os resultados obtidos naquela unidade de tratamento com a técnica proposta. As informações devem também atingir dados de caráter biológico, jurídico, ético e econômico ${ }^{2}$. No mesmo sentido, a Declaração Universal sobre Bioética e Direitos Humanos aborda, em seu artigo 6으, o princípio do 
consentimento, o qual preceitua que: Qualquer intervenção médica preventiva, diagnóstica e terapêutica só deve ser realizada com o consentimento prévio, livre e esclarecido do indivíduo envolvido, baseado em informação adequada ${ }^{8}$.

Atendo a reflexão à figura do doador ou doadora, de antemão observam-se as três características fundamentais do consentimento e suas especificidades para esta circunstância: 1) ser prévio, o que acarreta à pessoa doadora a obrigatoriedade de aquiescência anterior à utilização do material doado em RHA; 2) ser livre, o que remete à reflexão sobre o risco de limitação da liberdade da pessoa doadora em situação de vulnerabilidade socioeconômica, como relatado no estudo de Samrsla e colaboradores ${ }^{10}$, em que mulheres expressaram a vontade de doar óvulos em troca de financiamento para os seus tratamentos; 3 ) ser esclarecido, isto é, dirigido à pessoa doadora em vocabulário compreensível, baseado em informação adequada, que inclui a comunicação sobre o sigilo a respeito de seus dados sociais e biológicos, segredo esse que pode vir a ser rompido segundo os debates em prol de eventual quebra de confidencialidade posterior.

A Resolução CFM 2.013/13 defende a ideia de que a identidade do doador e a do receptor não podem ser por eles conhecidas reciprocamente, obrigando os médicos à manutenção do sigilo de ambas as identidades. Permite, tão somente, a quebra relativa do sigilo, a qual não é absoluta, pois requer a motivação de saúde e o resguardo da identidade civil. Para esse fim, a Resolução determina que as clínicas, centros ou serviços que empregam a doação devem manter, de forma permanente, um registro de dados clínicos de caráter geral, características fenotípicas e uma amostra de material celular dos doadores ${ }^{2}$.

Observa-se, assim, que o anonimato do doador ou da doadora, constante em contrato para redução a termo dos acordos e normas estabelecidas entre as partes, é hoje condição precípua para a realização da doação. Segundo Zanatta e Enricone, o objetivo de estabelecer essas normas entre os sujeitos que participam das técnicas de RNA, dentre eles os doadores, é conferir segurança e estabilidade. Para os autores, tal segurança existe no sentido de que é realizado contrato onde o doador concorda em ter sua identidade preservada, bem como manifesta o seu desinteresse em conhecer a identidade dos beneficiários. Do mesmo modo, os beneficiários concordam em não conhecer a identidade do doador anônimo ${ }^{17}$.

Tal ponderação envolve, ainda, por necessária constituição da relação entre médicos e pacientes, o compromisso de sigilo médico. Nesses termos, somam-se o direito ao anonimato e a confidencialidade, exigências contratuais e ético-normativas.

Igualmente, o Código de Ética Médica trata, no capítulo IX, de questões sobre o sigilo profissional: veda ao médico, em seu artigo 73 , revelar fato de que tenha conhecimento em virtude do exercício de sua profissão, salvo por motivo justo, dever legal ou consentimento, por escrito, do paciente ${ }^{18}$. Portanto, a) motivo justo, situação em que se compreende ser justa a causa para o rompimento da confidencialidade; b) dever legal, em que doenças de notificação compulsória precisam ser informadas aos órgãos públicos e; c) consentimento por escrito do paciente, em que há declaração expressa da anuência pela divulgação da informação sigilosa, são as situações permitidas pelas normativas éticas médicas para revelação de dados profissionalmente adquiridos.

Nesse rumo, não havendo consentimento, já que os doadores contavam com o anonimato e apenas com a circunstância de quebra relativa do sigilo de informação genética, por razão de saúde, somente para a equipe médica, a pergunta que ora se faz necessária é: o conhecimento sobre a origem biológica como direito de um indivíduo que procura o médico responsável pela técnica de RHA que o gerou é um motivo justo? Para refletir sobre tal questão, é indispensável ponderar, anteriormente, a respeito da possível constituição desse direito.

\section{Identidade genética e direito ao conhecimento da "origem biológica"}

Teixeira e Moreira, ao discutirem a identidade genética no Brasil, afirmam que não há que se falar em uma única forma de identidade, mas uma pluralidade de identidades, que se constituem e reconstituem em uma rede de interlocuções e interdependência ${ }^{19}$. Apresentam-na, em seguida, como um reflexo do exercício da autonomia privada, cabendo ao indivíduo fazer escolhas e definir seus conteúdos em prol do reconhecimento de seu contexto e da compreensão de si perante o mundo.

Paralelamente, o direito à identidade genética é construído com base no direito à intimidade e à privacidade e no princípio fundamental da dignidade humana, todos presentes no texto da Constituição Federal de $1988^{20}$ e componentes do direito à identidade pessoal, em observância às dimensões individual e relacional de um indivíduo singular. Essa análise se consubstancia, sobretudo, na possível identificação da matriz biológica do sujeito ${ }^{19}$, o que lhe confere a 
prerrogativa sobre os bens biológicos que o identificam, dentre eles o conhecimento da sua origem.

É nesse sentido que o artigo 3ㅇda Declaração Internacional sobre os Dados Genéticos Humanos, da Unesco, remete à identidade da pessoa, aduzindo que cada indivíduo tem uma constituição genética característica. No entanto, não se pode reduzir a identidade de uma pessoa a características genéticas, uma vez que ela é constituída pela intervenção de complexos fatores educativos, ambientais e pessoais, bem como de relações afetivas, sociais, espirituais e culturais com outros indivíduos, e implica um elemento de liberdade ${ }^{21}$.

Acrescente-se a essa disposição, segundo o artigo 7ํ da Declaração Universal sobre o Genoma Humano e os Direitos Humanos, também da Unesco, que os dados genéticos associados a indivíduo identificável, armazenados ou processados para uso em pesquisa ou para qualquer outro uso, devem ter sua confidencialidade assegurada, nas condições estabelecidas pela legislação ${ }^{22}$. Ocorre que são acordantes os sujeitos doadores e os que pretendem ter filhos, mas não os filhos em si, advindos dessas técnicas heterólogas.

\section{Analogia com a legislação relativa à adoção no Brasil}

Para Pedrosa Neto e Franco Júnior ${ }^{23}$, após a instituição das novas tecnologias de RHA, tanto a maternidade quanto a paternidade ou a perspectiva estendida de família podem ser constituídas - legal e eticamente - sem o vínculo genético, situação que já contava como exemplo e afirmação o instituto da adoção. Já no Acordo de Reñaca ${ }^{24}$, celebrado em 1995 entre os países da América Latina, a reprodução heteróloga era entendida como prática aceitável, por sua analogia com o vínculo criado entre pais sociais e filhos em casos de adoção.

Atendo-se à dimensão relacional, Salles ${ }^{25}$ discorre sobre a estreita ligação entre identidade e o direito à historicidade pessoal. Segundo o autor, tal conceito é consubstanciado por Otero em sua obra "Personalidade e identidade pessoal e genética do ser humano", de 1999, em que aponta como direito de cada ser humano conhecer a respectiva origem e o patrimônio genético, elemento relevante para prevenção de certas doenças e ao desenvolvimento da personalidade. Significa que cada ser humano tem o direito de conhecer a identidade dos seus progenitores, ou seja, quem são seus pais biológicos ${ }^{26}$.

A Lei 12.010/09 ${ }^{27}$, que dispõe sobre adoção, traz em seu artigo 48 a discussão acerca do direito ao conhecimento da origem biológica, alterando seguidamente o Estatuto da Criança e do Adolescente (ECA) ${ }^{28}$ : $O$ adotado tem direito de conhecer sua origem biológica, bem como de obter acesso irrestrito ao processo no qual a medida foi aplicada e seus eventuais incidentes, após completar 18 (dezoito) anos ${ }^{27}$. Garante, inclusive, a prática desse direito pelo adotado menor, assegurando-lhe $a$ orientação e a assistência jurídica e psicológica. Ao conceder a permissão ao indivíduo adotado de conhecimento sobre a sua origem biológica, a Lei de Adoção está considerando o seu direito à historicidade pessoal ${ }^{26}$.

É importante assinalar a similaridade de circunstâncias entre os dois cenários: a adoção e a RHA. Na primeira situação estão presentes: a) os pais biológicos, que por via natural conceberam o indivíduo; b) aqueles que adotaram, os pais socioafetivos; c) as pessoas adotadas, que passam a buscar o direito ao conhecimento de suas origens biológicas. No caso da RHA, existem, igualmente: a) os pais biológicos, que são os doadores de material germinativo; b) os pais socioafetivos, que são aqueles que utilizaram as técnicas de RHA e que portaram o efetivo intuito de ter filhos; c) a pessoa nascida, que agora reclama pelo conhecimento de sua historicidade.

De todo modo, para prosseguir na possibilidade dessa analogia, é indispensável a percepção de que, assim como no instituto da adoção, a constituição de vínculo familiar socioafetivo deve ser irrevogável, não sendo restabelecido o vínculo familiar jurídico com os doadores de material germinativo nem sequer com a morte dos pais socialmente considerados.

\section{O "pertencimento" do segredo}

Para a continuidade da reflexão ética, a interrogação que se faz necessária refere-se a quem pertence o segredo (pertencimento do segredo) sobre as informações genéticas do doador. Que pertence ao doador o segredo sobre os seus dados, uma vez que se trata de informações genéticas e sociais da alçada de sua intimidade e defendidas constitucionalmente, ao que parece não pairam dúvidas. Entretanto, em relação à pessoa nascida, a reflexão que o presente estudo propõe é sobre o seu pertencimento concomitante, que incidiria ao lado do pertencimento da pessoa doadora na medida em que portaria o direito de conhecer sua origem biológica, em um esforço para a constituição da sua identidade social, subjetiva e genética. 
Assim, o quadro estudado mostra a contradição entre o direito à intimidade do doador e o direito da pessoa gerada de conhecer sua origem biológica, na medida em que há discordância sobre a revelação do segredo. Se, por um lado, há quem pense que manter o anonimato é importante, tendo em vista a necessidade de evitar futuras situações anômalas emocionais e legais entre doadores, receptores e pessoas nascidas, por outro, há os que defendem o direito à identidade pessoal e ao conhecimento acerca da ascendência genética dessas pessoas, que coadunam com seus direitos da personalidade, decorrentes do respeito à dignidade da pessoa humana.

Igualmente, considera-se importante o conhecimento, por parte da pessoa nascida, da identidade de seus genitores biológicos, entretanto sem consequências jurídicas correlatas, como herança e direito ao nome, devido à natureza do procedimento, que confere a ausência de intento de procriação e tão somente mera doação de material germinativo por parte dos doadores. Conforme reflete Costa, a atribuição de maternidade e paternidade no uso das tecnologias reprodutivas permite a separação da ideia de reprodução dos elementos femininos e masculinos participantes desse processo. Para tanto, a autora discute que tais questões referem-se ao julgamento de qual destes elementos (relação entre o casal, os gametas ou a gravidez) será considerado como o mais importante na atribuição da maternidade e da paternidade ${ }^{29}$.

Nesse contexto, há quem defenda a constituição da filiação e estabelecimento de maternidade e paternidade como conceitos efetivamente relacionais, sendo essa uma relação de parentesco que se estabelece entre duas pessoas, uma das quais é considerada filha da outra ${ }^{30}$. De acordo com esse raciocínio, a filiação seria decorrente do estabelecimento de laços afetivos construídos cotidianamente, que valorizam o vínculo social além do vínculo biológico.

\section{Pais socioafetivos e a "desbiologização"}

Havendo vínculos formados com os pais socioafetivos, o conhecimento da origem biológica pela pessoa gerada pode vir a não implicar a construção de relações de parentesco ou geração de obrigações morais ou legais para os doadores, ainda que afete a essência do acordo em que houve a doação e o uso de material germinativo. Entretanto, os riscos sociais relacionados com a execução da técnica, vistos de forma mais ampla, requerem também uma reflexão sobre gênero e vulnerabilidade dos sujeitos receptores, considerados pais socioafetivos.
Ao realizar estudo objetivando a identificação da intenção de revelar a ovodoação aos filhos, familiares e amigos, Montagnini, Malerbi e Cedenho afirmam a complexidade da questão do sigilo sobre doação de gametas, que não pode ser desconsiderada ou respondida com regras simples e gerais, devendo-se levar em consideração as especificidades de cada família e seu contexto. Afirmam, ainda, que a decisão de revelar ou não para o filho sua origem é um dos desdobramentos inevitáveis com os quais os casais que participam dos programas de reprodução assistida irão se deparar no futuro, e está longe de ser algo simples ${ }^{31}$.

Lembrando os aspectos positivos de passar a informação aos filhos, esses autores apontam também que, assim como no instituto da adoção, poder-se-ia supor que a ausência de conhecimento ou informação sobre a origem pode ser prejudicial à criança e consequentemente ao relacionamento familiar $^{31}$. Mostram dados de entrevistas feitas com casais receptores, questionados sobre os motivos que os levariam a revelar ao filho a técnica com que ele foi gerado e a utilização de material genético de doador. Muitos casais entrevistados expressaram receio na revelação, mostrando a intenção de revelar a completude dos fatos somente se fosse realmente perceptível não serem os pais biológicos, como acontece em diversas situações de adoção nas quais não houve o período de gestação e exibição social das consideradas maternidade e paternidade. Dentre esses receios, é forte a presença do medo das repercussões emocionais no filho, bem como que ele descubra por outros meios que não o diálogo com os pais. Também se observou na referida pesquisa que, quando eram reduzidas as chances de que outras pessoas revelassem ao filho ou que ele descobrisse por algum meio, era bem baixa a intenção dos pais em revelar.

A respeito da quebra de sigilo do doador nas técnicas de RHA, Diniz aponta que argumentos como direito ao reconhecimento das origens ou direito à identidade biológica contêm fundamentos morais, ressaltando que, apesar disso, não são necessariamente defensáveis segundo a atual perspectiva constitucional brasileira. $\mathrm{O}$ autor discorre ainda sobre a temática, acrescentando que o rompimento do sigilo surge como estratégia para coibir a possibilidade de que outros arranjos matrimoniais que não a família heterossexual tenham acesso às técnicas, uma vez que poucas pessoas se prontificarão a doar esperma ou óvulo diante do risco de identificação futura e das consequências jurídicas do ato. Igualmente, afirma estar presente nesse 
contexto o que denomina de subterfúgio argumentativo $^{32}$, visto que se trataria de um apelo à autonomia da futura criança com o objetivo, em verdade, de limitar o acesso de mulheres sem cônjuges e de casais homossexuais às novas técnicas reprodutivas.

A crítica, portanto, volta-se para a possibilidade de utilização de critérios unicamente biológicos nos argumentos, que contrariam a perspectiva de família como entes relacionais em seus papéis sociais. Coerente com essa reflexão está a proposta de desbiologização dos conceitos de maternidade e paternidade, que também está presente a partir de uma analogia e leitura crítica da própria Lei de Adoção, já que confere aos filhos a constituição irrevogável de famílias sem necessário vínculo biológico, valorizando sobretudo o direito das crianças e adolescentes à convivência familiar ${ }^{27}$.

Nesse sentido também tem se posicionado a jurisprudência do Supremo Tribunal Federal, em 2011, em Ação Declaratória de Paternidade Socioafetiva, que discutia a desbiologização da paternidade: A tese da posse do estado de filho como fato gerador de efeitos jurídicos capazes de definir a filiação nos leva a questionar se a verdadeira paternidade se explica apenas pela genética. Sabemos que não. Tanto que a legislação veio ampliar o instituto jurídico da adoção, consagrado na Constituição Federal que, no art. 226, \& 60 concede aos filhos, havidos ou não das relações do casamento ou por adoção os mesmos direitos e qualificações, proibidas quaisquer designações discriminatórias relativas à filiação ${ }^{33}$.

\section{Considerações finais}

Pelo exposto, observa-se que a ausência de legislação sobre RHA tem ensejado importantes debates bioéticos e jurídicos, demandando reflexões que antecederão as leis. A partir da aplicação das técnicas de RHA no Brasil, têm surgido situações e conflitos emergentes e persistentes, de modo que o enfrentamento ético perpassa tanto a conjuntura vinculada à utilização das novas tecnologias, quanto as questões socioeconômicas relacionadas com o acesso à saúde e as questões de gênero.

A discussão acerca da possibilidade de compreensão do conhecimento da origem biológica como um direito da pessoa gerada por técnica de RHA heteróloga traz argumentos que ainda são controversos. Temas como sexualidade e procriação terminam por compor a reflexão, sobretudo no contexto moral brasileiro, em que as diversas constituições familiares ainda permanecem como alvo de debate, apesar das normativas constitucionais a favor da igualdade.

Normatizando a prática da RHA no Brasil, o CFM tem apresentado, por meio de suas resoluções, elementos adequados para organização do exercício médico profissional, proporcionando a utilização ética dessas novas tecnologias e as reflexões bioéticas que delas advêm. Após admitir como pacientes todas as pessoas capazes, a Resolução CFM 2.013/13 proporcionou um avanço no que diz respeito às individualidades. Entretanto, a questão que se apresenta é a possível legitimidade da proteção dos interesses da pessoa gerada em conhecer sua origem biológica, o que rompe com as demais normativas concernentes ao sigilo, e que envolvem as reflexões sobre confidencialidade médica e autonomia dos sujeitos.

Diante de condições de vulnerabilidade em que se inserem os atores envolvidos na circunstância, destacam-se os doadores, os receptores ou pais socioafetivos e os filhos gerados. Mantêm-se, então, três campos de análise: o suposto direito ao conhecimento da origem biológica, a reflexão sobre o pertencimento do segredo e a desbiologização das condições de maternidade e paternidade sociais. Nesses termos, observa-se que, mesmo fazendo analogia com os preceitos da adoção no Brasil, em que não se daria o estabelecimento de vínculo familiar ou obrigações jurídicas, a questão não é facilmente resolvida, mantendo-se presente a complexidade da circunstância e de seus desdobramentos éticos correlatos, que não podem ser ignorados.

Trabalho produzido no âmbito do Programa de Pós-graduação em Bioética da Universidade de Brasília (UnB).

\section{Referências}

1. Taitson PF. Normatização brasileira em reprodução humana. In: Casabona CMR, Freire de Sá MF, coordenadores. Direito biomédico: Espanha-Brasil. Belo Horizonte: Editora PUC Minas; 2011. p. 224-37. 
2. Conselho Federal de Medicina. Resolução CFM no 2.013, de 16 de abril de 2013. Adota as normas éticas para a utilização das técnicas de reprodução assistida, anexas à presente resolução, como dispositivo deontológico a ser seguido pelos médicos e revoga a Resolução CFM no 1.957/10. [Internet]. 9 maio 2013 [acesso 19 nov 2013]. Disponível: http://www.portalmedico.org.br/ resolucoes/CFM/2013/2013_2013.pdf

3. Brasil. Lei no 10.406 , de 10 de janeiro de 2002. Institui o Código Civil. Diário Oficial da União. [Internet]. 11 jan 2002 [acesso 3 out 2012]. Disponível: http://www.planalto.gov.br/ccivil_03/ leis/2002/I10406.htm

4. Donizetti L. Filiação socioafetiva e direito à identidade genética. Rio de Janeiro: LumenJuris; 2007. p. 117.

5. Garrafa V. Bioética e ciência: até onde avançar sem agredir. In: Costa SIF, Oselka G, Garrafa V, coordenadores. Iniciação à bioética. Brasília: Conselho Federal de Medicina; 1998. p. 100.

6. Meira AR, Gattás GJF. Da fecundação humana extracorpórea à clonagem: quem são os pais? Bioética. 2005;13(1):69-73.

7. Beauchamp TL, Childress JF. Principles of biomedical ethics. 7ạ ed. Nova York: Oxford University Press; 2013.

8. Organização das Nações Unidas para a Educação, a Ciência e a Cultura. Declaração Universal sobre Bioética e Direitos Humanos. [Internet]. Paris: Unesco; 2005 [acesso 21 set 2012]. Disponível: http://bvsms.saude.gov.br/bvs/publicacoes/declaracao_univ_bioetica_dir_hum.pdf

9. Jonas H. O princípio da responsabilidade: ensaio de uma ética para a civilização tecnológica. Rio de Janeiro: Contraponto; 2006.

10. Samsrla M, Nunes JC, Kalume C, Cunha ACR, Garrafa V. Expectativa de mulheres à espera de reprodução assistida em hospital público do DF: estudo bioético. Rev Assoc Med Bras. 2007;53(1):47-52.

11. Corrêa M. Medicina reprodutiva e desejo de filhos. In: Grossi M, Porto R, Tamanini M, organizadores. Novas tecnologias reprodutivas conceptivas: questões e desafios. Brasília: Letras Livres; 2003. p. 31-8.

12. Mori M. Fecundação assistida e liberdade de procriação. Bioética. 2002;9(2):57-70.

13. Dias MB. Manual de direito das famílias. São Paulo: Editora Revista dos Tribunais; 2006. p. 43.

14. Conselho Federal de Medicina. Resolução CFM no 1.358, de 11 de novembro de 1992. Adota normas éticas para utilização das técnicas de reprodução assistida. [Internet]. 19 nov 1992 [acesso 3 out 2012]. Disponível: http://www.portalmedico.org.br/resolucoes/CFM/1992/1358_1992.htm

15. Conselho Federal de Medicina. Resolução CFM no 1.957, de 15 de dezembro de 2010. A Resolução CFM no 1.358/92, após 18 anos de vigência, recebeu modificações relativas à reprodução assistida, o que gerou a presente resolução, que a substitui in totum. [Internet]. 6 jan 2011 [acesso 3 out 2012]. Disponível: http://www.portalmedico.org.br/resolucoes/CFM/2010/1957_2010.pdf

16. Corrêa M, Diniz D. Novas tecnologias reprodutivas no Brasil: um debate à espera de regulação. In: Carneiro F, Emerick MC, organizadores. A ética e o debate jurídico sobre acesso e uso do genoma humano. Rio de Janeiro: Fiocruz; 2000. p. 103-12.

17. Zanatta AM, Enricone G. Inseminação artificial: doação anônima de sêmen e a possibilidade jurídica de quebra de sigilo. Perspectiva. 2010;34(126):103.

18. Conselho Federal de Medicina. Resolução CFM no 1.931, de 17 de setembro de 2009. Aprova o Código de Ética Médica. [Internet]. 24 set 2009 [acesso 3 out 2012]. Disponível: http://www. portalmedico.org.br/novocodigo/integra.asp

19. Teixeira ACB, Moreira DL. A identidade genética e seus reflexos no direito brasileiro. In: Casabona CMR, Freire de Sá MF, coordenadores. Direito biomédico: Espanha-Brasil. Belo Horizonte: Editora PUC Minas; 2011. p. 115.

20. Brasil. Constituição da República Federativa do Brasil. Brasília: Senado Federal; 1988.

21. Organização das Nações Unidas para a Educação, a Ciência e a Cultura. Declaração Internacional sobre os Dados Genéticos Humanos. [Internet]. Unesco; 2004 [acesso 21 set 2012]. Disponível: http://www.unescobkk.org/fileadmin/user_upload/shs/BEfiles/chapterC.por/C10P.pdf

22. Organização das Nações Unidas para a Educação, a Ciência e a Cultura. Declaração Universal sobre o Genoma Humano e os Direitos Humanos: da teoria a prática. Brasília: Unesco; 2001 [acesso 21 set 2012]. Disponível: http://unesdoc.unesco.org/images/0012/001229/122990por.pdf

23. Pedrosa Neto AH, Franco Júnior JG. Reprodução assistida. In: Costa SIF, Garrafa V, Oselka G, coordenadores. Iniciação à bioética. Brasília: Conselho Federal de Medicina; 1998. p. 111-24.

24. Red Latinoamericana de Reproducción Asistida. Consenso latinoamericano en aspectos éticolegales relativos a las técnicas de reproducción asistida. Reñaca, Chile, 1995. Marzo, 1996. Cad Saúde Pública [Internet]. 1998;14(suppl 1):S140-6. Disponível: http://dx.doi.org/10.1590/S0102$311 \times 1998000500026$

25. Salles RC. O direito à identidade genética e o estado de filiação: análise dos critérios definidores do vínculo de filiação e o direito ao conhecimento da origem biológica. Revista do Ministério Público do Distrito Federal e Territórios. 2010;4:171-207.

26. Salles RC. Op. cit. p. 190.

27. Brasil. Lei no 12.010, de 3 de agosto de 2009. Dispõe sobre adoção. Diário Oficial da União. [Internet]. 4 ago 2009 [acesso 3 out 2012]. Disponível: http://www.planalto.gov.br/ccivil_03/_ Ato2007-2010/2009/Lei/L12010.htm 
28. Brasil. Lei no 8.069, de 13 de julho de 1990. Dispõe sobre o Estatuto da Criança e do Adolescente e dá outras providências. Diário Oficial da União. [Internet]. 16 jul 1990 [acesso 3 out 2012]. Disponível: http://www.planalto.gov.br/ccivil_03/leis/l8069.htm

29. Costa RG. Reprodução e gênero: paternidades, masculinidades e teorias da concepção. Rev Estud Fem. [Internet]. 2002[acesso out 2012];10(2):343. Disponível: http://dx.doi.org/10.1590/S0104026X2002000200005

30. Lobo PLN. Direito ao estado de filiação e direito à origem genética: uma distinção necessária. Revista CEJ. 2004;8(27):48.

31. Montagnini HML, Malerbi F, Cedenho AP. Ovodoação: a questão do sigilo. Estud Psicol (Campinas). 2012;29(2):232.

32. Diniz D. Tecnologias reprodutivas conceptivas: o estado da arte do debate legislativo brasileiro. Brasília: Letras Livres; 2004. p. 7. (Série Anis, 33).

33. Brasil. Supremo Tribunal Federal. Agravo de Instrumento no 746.096. Declaratória de paternidade sócio-afetiva posse do estado de filha, efeitos jurídicos, ingerência. Relator: Min. Dias Toffoli, julgado em 31 de agosto de 2011. Diário da Justiça Eletrônico. [Internet]. 6 set 2011[acesso 3 out 2012];(171). Disponível: http://www.stf.jus.br/portal/jurisprudencia/listarJurisprudencia. asp?s1=\%28\%28desbiologiza\%E7\%E30\%29\%29+NAO+S\%2EPRES\%2E\&base=baseMonocratica

\section{Participação dos autores}

Todos os autores participaram igualmente da revisão de literatura, discussão, elaboração do manuscrito e revisões finais.

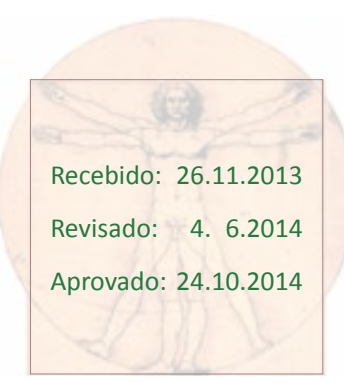

